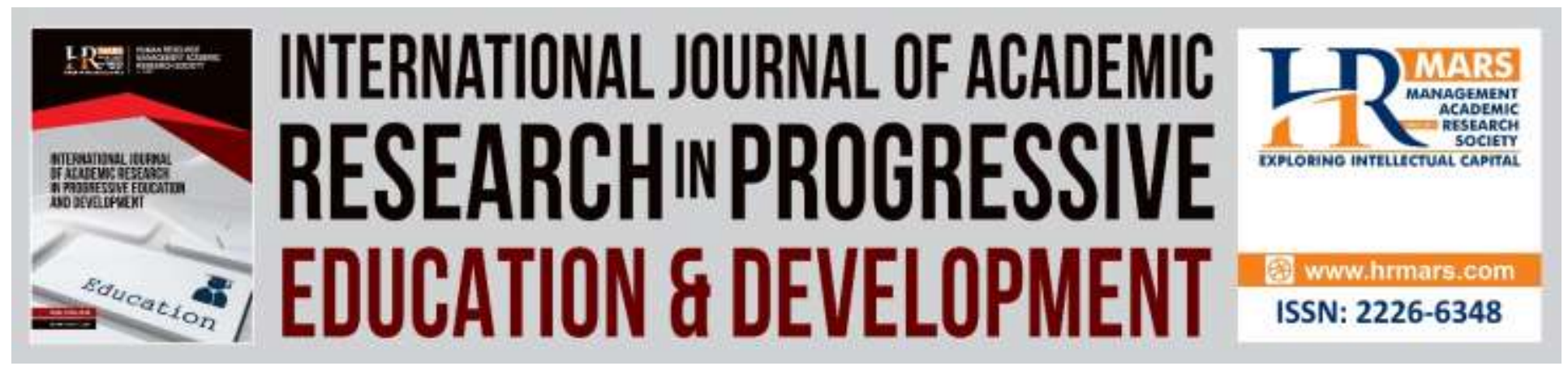

\title{
Relationship Between Social Media Usage and Academic Achievement amomg Tertiary Students in Malaysian Public University
}

Ibrahim Mohammed Hamad Amin, Norlizah C. Hassan \& Habibah Ab Jalil

To Link this Article: http://dx.doi.org/10.6007/IJARPED/v8-i4/6671

DOI:10.6007/IJARPED/v8-i4/6671

Received: 15 October 2019, Revised: 30 October 2019, Accepted: 11 November 2019

Published Online: 30 November 2019

In-Text Citation: (Amin, Hassan, \& Jalil, 2019)

To Cite this Article: Amin, I. M. H., Hassan, N. C., \& Jalil, H. A. (2019). Relationship Between Social Media Usage and Academic Achievement amomg Tertiary Students in Malaysian Public University. International Journal of Academic Research in Progressive Education and Development, 8(4), 627-642.

Copyright: (C) 2019 The Author(s)

Published by Human Resource Management Academic Research Society (www.hrmars.com)

This article is published under the Creative Commons Attribution (CC BY 4.0) license. Anyone may reproduce, distribute, translate and create derivative works of this article (for both commercial and non-commercial purposes), subject to full attribution to the original publication and authors. The full terms of this license may be seen

at: http://creativecommons.org/licences/by/4.0/legalcode

Vol. 8(4) 2019, Pg. 627 - 642

http://hrmars.com/index.php/pages/detail/IJARPED

JOURNAL HOMEPAGE

Full Terms \& Conditions of access and use can be found at http://hrmars.com/index.php/pages/detail/publication-ethics 


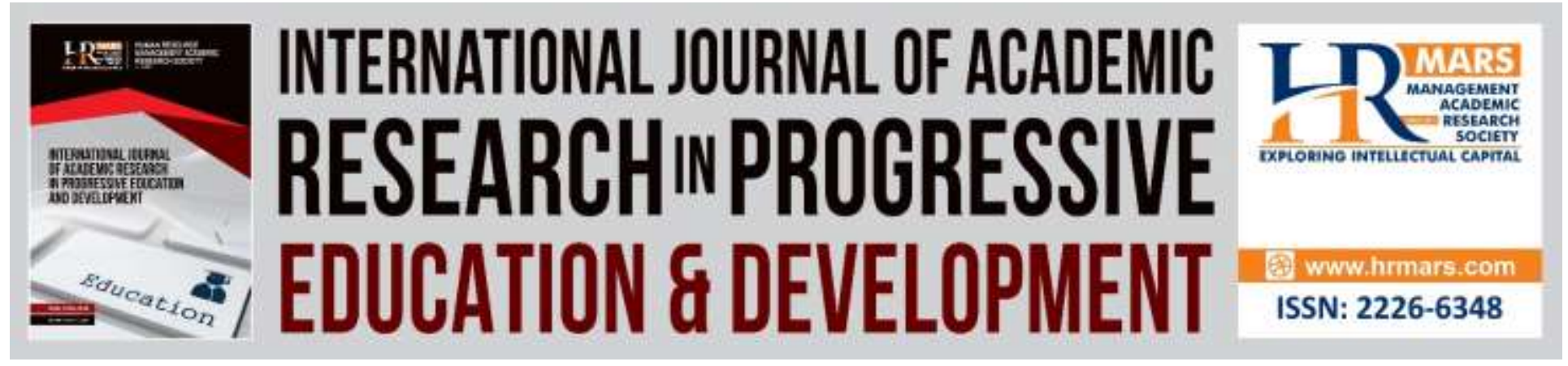

\title{
Relationship Between Social Media Usage and Academic Achievement amomg Tertiary Students in Malaysian Public University
}

\author{
Ibrahim Mohammed Hamad Amin, Norlizah C. Hassan \& Habibah \\ Ab Jalil
}

Faculty of Educational Studies, University Putra Malaysia, 43450, Serdang, Malaysia

\begin{abstract}
The increasing use of social media among tertiary students is one of the highly growing phenomena in the academia. Various studies show students' high involvement in using social media network to interact with their peers, lecturers and discussing learning materials. Full understanding of the social media and how it is being utilized in education is needed, especially in knowing the relationship between social media used and academic achievement among tertiary students as we know the tertiary students are at large used this technologies. The aims of this study is to examine the relationship between social media used (online peer learning) and academic achievement among tertiary students in one of the Malaysian public university. The study was based on quantitative method with a correlational design using questionnaires that was modified from previous study and validated by a panel of experts. The sampling technique was stratified from 17 faculties and 328 respondents involved in this study. There are positive significant low correlation between the variables measured. The highest correlation is between collaboration and academic achievement followed by the correlation between performance expectancy and academic achievement, engagement and academic achievement, social influence and academic achievement, peer feedback and academic achievement, and lastly, self-efficacy and academic achievement. Practical implications and recommendations were given to enhance the engagement of students via online peer learning.
\end{abstract}

Keywords: Social Media Usage, Academic Achievement, Tertiary Students, Public Universities.

\section{Introduction}

The increasing use of social media among tertiary students is one of the highly growing phenomena in the academia. Various studies showed students' high involvement in using social network websites to interact with their lecturers and discussing learning materials $(1,2,3)$. According to Kushin and Yamamoto (1), social media helps students to communicate, and create network with each other through comments, posts, and information sharing. From the observation, it is almost not surprising that a large number of students as a society of learners 
relying on different social media tools and websites in order to increase their academic achievement and this has been done through knowledge sharing activities, learning management in electronic learning (2). Hashim, Abdullah, Isa and Janor (3) acknowledged the expanding use of different social media tools all around the world. Different individuals across the global and through various disciplines are engaged with social media tools. Specifically, the Infographic Social Media Statistics (Infographic, 2014) testified that there is more than 700 million users access Facebook from 7000 different devices, more than 500 million users access Twitter, and more than 130 million uses Instagram in 2013. Elsewhere, Vezina (4) have been acknowledging YouTube, Twitter and Facebook in teaching and learning processes. In this case, the researchers have raised concerns that students must develop the ability to interact, work, communicate, find, and share knowledge consistent to present ever-changing E-learning environment. According to Kiss (5), in July 2010 more than 500 million members had been found as active users of Facebook. Considering its reputation among students, new version of Facebook high school was launched in September, 2005. Its members are multiplying greatly with each day passing. There are 2.41 billion active users as of the second quarter of 2019, Facebook is the biggest social network worldwide. In the third quarter of 2012, the number of active Facebook users surpassed one billion, making it the first social network ever to do so. Active users are those which have logged in to Facebook during the last 30 days. There are more than 3.5 billion pieces of content (web links, news stories, blog posts, etc.) shared each week on Facebook. Meanwhile in Malaysia, Facebook users are expected to reach 24.2 million, up from 22 million in 2017. It shows that Malaysia is in the $18^{\text {th }}$ ranking of all Facebook statistics by Country. Apart from facebook, other types of social media usage such as Twitter, WhatsApp, Instagram and Youtube are also increasing. As such, the cited findings on Facebook, You Tube and Twitter can enrich discussions on social media use (online peer-learning, and students' academic achievements). Yet, it seems that most of the previous studies were exploratory with limited focus to such issues as positive social relations along time spent on social media. That makes generalizability of much of published research to appear inconclusive and challenging at least at the scope of this study.

Academic achievement is one debated concept in educational policies and literature discourses and central to the discussion is social media websites which impact students' academic achievements. One thinkable explanation is that social media use relate with students' academic achievement. Attempts have been made to acknowledge tertiary students' views on the use of social media tools and academic performance in Malaysian context $(3,6)$. Understandably, most of tertiary students' in present Malaysian universities' setting, as in Western societies, consistently visit the Internet and email, text messaging and social media tools, which allow them to get engaged in online communities and share information in educational contexts. Online peer learning via social media as a "technique" is widely used to promote attainment in students." Students are motivated to learn, comprehend, and review material when they are put into a teaching task. In another definition, Keppel, Au, Ma and Chan (7) defined peer learning in relation to students learning from and with each other in both formal and informal ways. Researchers consider peer learning is all about ability to communicate and work together for improved results. In a very explicit and informative manner. 
Vol. 8, No. 4, 2019, E-ISSN: 2226-6348 @ 2019 HRMARS

Keppel, Au, Ma and Chan (7) reported that recent developments in social media have highlighted the need for considering the use of its different tools in higher education contexts. It is noted that peer learning takes place when "students discuss lectures, assignments, projects and exams in casual social settings". This discussion of online peer learning with the use of social media tools is needed as it cut across all objectives of the study. That is because the tertiary students have both formal and informal discussions and knowledge sharing sessions to adopt principles; construct lecture notes and tasks, infer rules for solving the problem and repair imperfect mental models.

Razak and See (6) did a study on improving academic achievement and motivation through online peer learning. The purpose was to examine the effectiveness of online peer learning in enhancing students' academic achievement and promoting their motivation through a quasinon-equivalent (pre and post-test) control group design to investigate the effectiveness of online peer learning. The findings of t-tests indicated that the experimental group reported a significant difference in motivation meaning a significant difference in academic achievement. In line with this research, the said findings seem to suggest that online peer learning can enhance students' academic achievement and facilitate their motivation. Equally, the said results seem to support other researchers (8) that online environment sustain learning through active and engaging activities and constructive learning opportunities rather than just be exposed to the transmission of knowledge.

Certainly, the said findings sound interesting and seem to add more on our understanding of the discussed topic. One major criticism against much of the cited works and related studies, however, is that they seem to emphasize standardization and neglect local perspectives. According to Kincheloe (9), the useful knowledge needs to be culturally produced in order to appreciate the world in a true sense. Therefore, a need arise to appreciate research on factors influencing online peer learning and academic achievement from Malaysian context, knowing that Malaysian tertiary students have a different cultural orientation as compared to other parts of the world. Al-Rahmi, Othman and Yusuf (10) conducted a study on the improvement of students' academic performance by using social media through collaborative learning in Malaysian higher education. The researchers sampled and studied both undergraduate and postgraduate students at University Teknologi Malaysia (UTM) to understand the impact of social media on academic performance and the possibility of using them as an effective pedagogical tool to improve academic performance. The findings show that social media affects positively and significantly collaborative learning of interaction with peers, interaction with supervisors, engagement, perceived ease of use, and perceived usefulness.

For that reason, given the pervasive nature of social media amongst university students, the said findings seemed encouraging provided that the university administration and academic teams will opt to connect students and deliver them instructional content in effective manner (10). The point by Al-Rahmi and colleagues suggest that there is a lack of evidence in Malaysian Higher Education context on the use of social media to improve performance of students towards what Al-Rahmi, et al. (10) called as desirable outcomes. Perhaps, following that observation, Al- 
Vol. 8, No. 4, 2019, E-ISSN: 2226-6348 @ 2019 HRMARS

Rahmi et al. (10), studied the role of social media for collaborative learning to improve academic performance of students and researchers in Malaysian Higher Education (tertiary students).

Cognitive Theory of Learning pointed out that collaboration between peers is necessary to exchange ideas and it can develop the peer capabilities. Collaborative learning has been found to be a driver for student's satisfaction and achievement in social media (10). This study has employed the social cognitive theory (SCT) developed by Albert Bandura (1986) as the ground theoretical appeal of the concept of self-efficacy. Certainly, newer forms of social media have the potential to reshape peer-to peer communication patterns, interaction and amplifying of their feelings, perspectives and sense of connectedness. According to Bandura, self-efficacy is the degree or strength of individual belief in their own capability and willingness to accomplish tasks and goals. Individuals with high self-efficacy have high expectation that outcomes or consequences of the tasks they perform must be effective, valuable, and beneficial to them and the reverse is true. In practice, self-efficacy is influenced by both individual's capability and surrounded people who may have a positive or negative attitude towards specific behaviour. Employing the concept of self-efficacy as developed in this theory is consistent with the ongoing research discussions which acknowledge, the increasing peer perceptions of preparedness for effective peer learning-driven forum in the context of technological advancement, information sharing and intervention (1). This theory is employed as having high self-efficacy is vital among tertiary students. High self-efficacy is one of the key contributing factor to help them perform better in online peer learning. Taken together, social cognitive theory is employed because it details how internal cognitions and environmental factors work in the bids to realise objectives of this study.

Yet, there has been inadequate discussion about relationship of social media tools and improvement of university students' academic achievement in Malaysian context (7). Studies conducted in Malaysia related to the said technological tools seemed silent on major success factors, benefits, and obstacles limiting their applications in learning institutions, despite their opportunities to facilitate meaningful knowledge in higher education (9), providing a rich context in which to examine this emerging phenomenon. The dimensions of online peer learning are incorporated based on the previous studies. Therefore, this study attempted to examine the relationship between social media used (online peer learning) and academic achievement among tertiary students in one of the Malaysian public university.

\section{Methods}

The study was based on the quantitative method in nature with a correlational design using a set of questionnaires as instrument adapted from previous study and validated by panel of experts. The population in this study were tertiary students from all 17 faculties at UPM (one of the public university in Malaysia). According to the university's administration office, the number of tertiary students in this public university were 17,582. Using the proportional stratified sampling, this study would ensure that sub-groups of undergraduates from different faculties in UPM would present results in the same proportion as they were in the population. The sampling technique was stratified from 17 faculties and a total of 328 respondents have been participated. As stated 
Vol. 8, No. 4, 2019, E-ISSN: 2226-6348 ㄷ 2019 HRMARS

by Cochran (11), the sample size of the population $(17,582)$ of this research at the margin error of $5 \%$ and degree of confidence of $95 \%$ is 328 respondents. The sample size for each faculty was calculated based on the percentage of the faculty in the population. The present study have applied the questionnaires by the measurement adapted from the National Survey of Student Engagement's (NSSE), the College Student Report with permission from Indiana University. A pilot study was carried out on (30) tertiary students which indicated Cronbach Alpha's value for the six factors studied ranges from 0.77 to 0.90 . Meanwhile, academic achievement was measured on the basis of the students' grade point average (GPA) scores for the semester in which the study was conducted.

\section{Results}

This section presents results and discussion on the findings of the study. Table 1 below presents the descriptive analysis of demographic background of the respondents such as gender, age group, length of usage on social media and social media application.

Table 1: Demographic Backgroud of the Respondents

\begin{tabular}{lll} 
Variables & Frequency & Percent \\
\hline $\begin{array}{l}\text { Gender } \\
\text { Male }\end{array}$ & 122 & 37.2 \\
Female & 206 & 62.8 \\
Age Group & & \\
$18-23 y r s$ & & \\
$24-29 y r s$ & 252 & 76.8 \\
$30-35 y r s$ & 74 & 22.6 \\
& 2 & 0.6 \\
Length of Social Media Usage & & \\
$1-3$ hours & 104 & 31.7 \\
$4-6$ hours & 109 & 33.2 \\
$7-9$ hours & 41 & 12.4 \\
$10-12$ hours & 64 & 19.4 \\
$13-15$ hours & 10 & 3.3 \\
& & \\
Social Media Application & & 62.5 \\
Facebook & 205 & 14.9 \\
YouTube & 49 & 1.8 \\
Twitter & 6 & 15.5 \\
WhatsApp & 51 & .3 \\
MySpace & 1 & 4.9 \\
Other & 16 & \\
\hline \hline
\end{tabular}


INTERNATIONAL JOURNAL OF ACADEMIC RESEARCH IN PROGRESSIVE EDUCATION AND DEVELOPMENT

Vol. 8, No. 4, 2019, E-ISSN: 2226-6348 ㄷ 2019 HRMARS

\section{Gender}

The results of gender distribution of respondents presented in Table 1 reveals that male constitutes only $37.2 \%$ (122), while female had about $62.8 \%$ (206). This indicates that majority of the respondents are female.

\section{Age Group}

Result from Table 1 revealed that age group of respondents' ranges between 18 to 35 years. However, about $76.80 \%$ (252) of the respondents falls between the age range of $18-23$ years old, $22.60 \%$ (74) were between the age range of $24-29$ years old and only $0.60 \%$ (2) attained $30-35$ years of age. The Mean age of respondents was 22.21 years ( $\approx 22$ years) with a standard deviation of 3.74 years ( $\approx 4$ years) which corresponds to those between the ages of $18-23$ years.

\section{Length of Social Media Usage}

The distribution of respondents based on hours spent on social media was categorized into five groups. The results indicate that respondents who spent about 1-3 hours on of their time on social media constitutes $31.70 \%$ (104), this is followed by the second group of 4-6 hours of usage, $33.20 \%$ (109), while the third group include those that spent $7-9$ hours with about $12.40 \%(41)$, the fourth group of 10-12 hours of usage were $19.40 \%$ (64) and finally, the fifth group of 13-15 hours of usage constitutes only $3.30 \%(10)$.

\section{Social Media Application}

With regards to social media application, the results indicate that about $62.50 \%$ of the respondents were Facebook users. Those who used YouTube were 14.90\% (49), Twitter users were $1.80 \%$ (6), WhatsApp users were $15.50 \%$ (51), MySpace user was only $0.30 \%(1)$ and users of other social media applications were $4.90 \%$ (16). The findings show that the tertiary students have access to social media and Facebook which is a tool that is mostly used by the students of the university. However, it is evident in the findings that Facebook is the most frequently used social media application as agreed by majority of the respondents. This verifies Ainin, Naqshbandi, Moghavvemi and Jaafar (12) findings, who noted that Facebook is the most used social media by students from five Malaysian universities.

The main aim of the study is to investigate the relationship between online peer learning and academic achievement. For this purpose, the Pearson correlation was utilized. The results on Pearson correlation analysis is presented in Table 2 below. 
Vol. 8, No. 4, 2019, E-ISSN: 2226-6348 @ 2019 HRMARS

Table 2: Correlation Between Social Media Usage (Peer Online Learning) and Academic achievement

\begin{tabular}{llllllll}
\hline \hline Variables & $\mathrm{X}_{1}$ & $\mathrm{X}_{\mathbf{2}}$ & $\mathrm{X}_{\mathbf{3}}$ & $\mathrm{X}_{\mathbf{4}}$ & $\mathrm{X}_{5}$ & $\mathrm{X}_{6}$ & $\mathrm{Y}$ \\
\hline $\mathrm{X}_{1}$ & 1 &. & & & & & \\
$\mathrm{X}_{2}$ & $.561^{* *}$ & 1 & & & & & \\
$\mathrm{X}_{3}$ & $.505^{* *}$ & $.456^{* *}$ & 1 & & & & \\
$\mathrm{X}_{4}$ & $.484^{* *}$ & $.425^{* *}$ & $.600^{* *}$ & 1 & & & \\
$\mathrm{X}_{5}$ & $.352^{* *}$ & $.226^{* *}$ & $.472^{* *}$ & $.561^{* *}$ & 1 & & \\
$\mathrm{X}_{6}$ & $.456^{* *}$ & $.443^{* *}$ & $.477^{* *}$ & $.613^{* *}$ & $.525^{* *}$ & 1 & \\
$\mathrm{Y}(\mathrm{CGPA})$ & $.255^{* *}$ & $.288^{* *}$ & $.280^{* *}$ & $.365^{* *}$ & $.285^{* *}$ & $.351^{* *}$ & 1 \\
\hline \hline
\end{tabular}

NB: $* *$ Significant at 0.01 .

\section{Students' Self-Efficacy and Academic Achievement}

The results of the students' self-efficacy and academic achievement while practicing online peer learning via social media showed that there is a significant relationship between these two variables. The Pearson correlation analysis has shown there is a significant low relationship ( $r=0.255^{* *}, p<0.01$ ) between students' self-efficacy and academic achievement. From the results, it was clearly shown that tertiary students have significant social confidence and readiness to abundantly participate in online peer learning. Such positive correlation might be due to the regular exposure and use of different emerging social media tools, both for learning or leisure quests (13). In discussing social media use as technology practice, this finding matches with observation by Wang and Wang (15), that as students' chances to use the technology in many times contributes more experiences and learning skills on the way. This observation sounds more vital in line of understanding students' online peer learning dynamics in achieving academic goals. A positive students' self-efficacy should be considered as one of the key component for what Wang and Wang (15) called as understanding students' achievement. Therefore, understanding changing relationship of students' self-efficacy is important in telling how a student can persist in online peer learning even at a time when the use of social media tool appears in line with comprehended of difficult learning tasks.

\section{Students' Engagement and Academic Achievement}

The students' engagement and academic achievement while practising online peer learning via social media was relationship sought in this study. The Pearson correlation analysis shown that there is a significant low correlation between students" engagement and academic achievement $\left(r=0.288^{* *}, p<0.01\right)$. Most of the students were skilful enough in the process of what Sedek (13) described as downloading e-books and creating presentations via technology, a thing that has positive relationship with academic achievement. Basically, the findings of the present study suggested that in order to promote relationship of students' engagement and academic achievement while practising online peer learning through the use of social media two scenarios must be interlinked. The first situation needs the students to have essential prior knowledge linked with relevant curriculum and engaging learning tasks in place. It is important that all these issues match with students' interests and expectations consistent to the aspired educational 
achievement.

The second condition is that students' engagement in practising online peer learning need to relate students' goals and willingness to persist. At this respect, students' engagement needs to be seen as an opportunity, to what is said by Sullivan and McDonough (14) as students' meaningful participation in learning for reasonable accomplishment. One possible explanation for such findings is that the use of social media tools as a platform of online peer learning is highly recommended, as their academic achievements are correlated with the peer online engagement. Therefore, lecturers need to consider changing of teaching approaches in favour of students' active engaged participation and sharing in order to achieve education success among tertiary students.

\section{Students' Peer Feedback and Academic Achievement}

The students' peer feedback and academic achievement was another important combination studied in this research. The results on peer feedback and academic achievement $\left(r=0.280^{* *}\right.$, $\mathrm{p}<0.01$ ) was recorded to confirm the significant relationship between those two variables. Peer feedback seemed to appear as an essential aspect of the tertiary students' learning process. This means, peer feedback could be thoroughly related to student's academic development. The current study findings by Ahmad, Saeed and Salam (22) could be due to the reality of the time that university learning offers what seems to be a station stage in students' life. It serves as a linkage stage between elementary stage and higher education of the learner. It is a vital subsystem of the educational system as it provides the work force for the national economy.

These findings seemed to be consistent with other study by Hattie and Timperley (23) that peer feedback is one of the most powerful influences on learning and achievement both positive and negative. This finding could be due to the reasons that peer as teacher feedback could be run as responses for students' performances. In this respect, it can be used to know how peers respond to other peers as students upon demonstration of knowledge, reasoning, skill or performance (22). For that reason, peers are obligated to encourage meaningful construction of knowledge and understanding of the concepts useful to the academic achievement.

Furthermore, even lecturers could be encouraged to opportune undergraduate students with constructive and engaging learning tasks to discuss their ideas about subjects through social media tools. That could be positive attempt towards meaningful online peer learning. As O'Connell (24) maintained that where people work in relationships and in which each individual experiences mutual dependencies, they achieve more individually. Thus, with caring peer feedback it could be likely for peers to achieve significant academic results.

\section{Students' Collaboration and Academic Achievement}

The students' collaboration and academic achievement was another significant mixture studied in this research. The results of Pearson correlation analysis of the two variables showed $\left(r=.35^{* *}\right.$, $p<0.1$ ). This might mean that tertiary students were keen to participate in online learning via the use of social media tools with strong feelings of connection. This finding suggests that most students had positive feeling consistent a sense of belonging and trust between peers as a way 
to recognize their collaboration as a valuable learning experience for academic achievement. Interestingly, although students in this study were able to meet face-to-face with other peers at university learning setting, still they seemed to display a strong feeling and need to engage in online social interaction. This was perhaps due to the social cultural settings in Malaysia as nonWestern context encourages community living and interactions amongst people.

\section{Students' Social Influence and Academic Achievement}

The students' social influence and academic achievement was significantly correlated. It is shown in the findings, the correlation between social influence and academic achievement is $\left(r=0.285^{* *}\right.$, $\mathrm{p}<0.01)$. These findings indicated that tertiary students were socialized by peers and other people with whom they were associating on daily basis to the extent of developing acceptable commitments to online peer learning. In this respect, it can be reasoned that the peers that the students interact with and spend time to share knowledge, skills and experiences through social media tools set parameter for their academic achievement. For that reason, social influence is important component in discussing students' achievements. Similar findings were reported by Korir and Kipkemboi (18) on a study examined the impact of school environment and peer influence on the students' academic performance. Their findings showed that school environment and peer influence made significant contribution to the students' academic performance.

The importance of social influence for academic achievement is evident and vital in helping students' learning and understanding. Research by Eamon (19) showed that students who trust their peers and teachers are more motivated and as a result perform better in school. This might be due to the reason that having constructive interactions with peers both inside and outside formal setting is important in the attempts of developing feeling of being secured which offers vital ground for judging their performance. These findings seemed to be consistent with other studies by Korir and Kipkemboi (18) and Qin, Kim, Hsu and Tan (20) that relationship of social influence to learn is an issue of importance because it guides individual decisions and reaction to achieved learning outcome. More captivatingly, elsewhere it is reported that by Ganotice and King (21) peer support seemed to be more leading compared to parental and teacher support both positively and negatively. Therefore, it is vital for university students to have friends who display constructive attitudes toward learning and overall academic achievement.

\section{Students' Performance Expectancy and Academic Achievement}

The students' performance expectancy and academic achievement was another interested thing in this study. The results showed that $\left(r=0.351, p<01^{* *}\right)$ meaning that there is significant positive relationship and high correlation between the said variables $A$ possible explanation for these findings might be that the tertiary students have developed prior expectations that their interactions with peers is vital for learning. That experience has created a sense of self-fulfilling perceptions and perpetual convictions that the use of social media tools along peer learning can assist them to realise their academic expectations. This sort of relationship suggested that the higher the students' expectations were for networked peers the higher their achievement. These results seemed to be consistent with the research by Cho, Cheng and Lai (16), performance 
Vol. 8, No. 4, 2019, E-ISSN: 2226-6348 @ 2019 HRMARS

expectancy can assist students' learning. In essence, the message here emerges that having higher expectation is an asset to realisation of higher academic achievements.

Those tertiary students in this study showed high expectation in performance need to cope to the rate of peer interactions consistent to changing uses of social media tools. In this respect, having positive performance expectance was found critical, in online peer-learning (16). These findings suggested that, most of respondents had particular interest on online peer learning as reflected by commitment on using different versions of social media tools. These findings indicated that the respondents were inquisitive enough to capitalize their networked learning environment at university, expecting to learn and achieve considerable academic outcome. In practice, such students' beliefs were important in changing their behaviors consistent to such ingredients confirming the first expectations. Within the present scope of discussed academic achievements, it is comprehensible that undergraduate students need to be prepared to have constructive expectations for positive learning performance. This confirms prior evidences by Hashim (3), and Yeung and Jordan (17) that there is a significant positive impact of performance expectancy and students' academic achievements. Hence, it is good to have positive expectations for significant academic achievement.

\section{Discussion}

It is evident from the reviewed literature that self-efficacy, collaboration between peers, engagement and feedback from others are vital in the discussion of factors that influencing students' academic achievement. Tertiary students, in this case, who are at large exposed to the social media may experience positive relationship that consistent with their academic achievement. However, there are yet relatively a few researchers' attempts to combine six factors and hypothesize their relationship with students' academic achievement in Malaysian tertiary level context. Based on the literature review, therefore, this study attempted to investigates the relationship between social media usage (online peer learning) and academic achievement among the tertiary students in one of the Malaysian public university.

From the reviewed literature there is no doubt that online peer learning via social media has correlated with tertiary students' academic achievements. Remarkably, it is recorded that students are keen to choose peers with whom they will live and learn for the duration of their life lived interaction (13). Based on the descriptive analysis that has been conducted on the data, the following recommendations can be given to the decision makers to enhance the utilization of social media and online peer learning. The findings of this study can be utilized by the decision makers at tertiary level. Factors that can affect the academic achievement were identified based on empirical approach. Decision makers at the tertiary level are advised to focus on self-efficacy because it is important for effective utilization of social media among tertiary students. Higher institutions can increase their students' self-efficacy by training them and holding workshops to sharpen their skills of using new technology so that they can grab the benefits of social media in order to enhance their academic achievement.

Based on the descriptive analysis and the mean score value of the variable (engagement), it is 
recommended for the decision makers to regulate the use of online peer learning via social media so that students can work with each other during the class time. Creating such culture can increase the students' participation and cooperation under the supervision of their lecturers. To train students to be more engaged in productive discussion via social media, lecturers can give homework and assignment that enforce students to develop the skills of working with each other in social media. A head of group can be assigned to monitor the work of students and the final summarized report can be sent to the lecturer. Based on the report, lecturers can reward those who have been highly engaged in the groups and this will motivate others to increase their engagement.

Descriptive analysis showed that students have concern over their grade when they are using social media. The university is recommended to set the role of using social media and to educate the students on the role and benefits of social media tools. The university can create a page or a portal for a specific class or subject, which is administrated by the lecturer of the subject. Extra point or rewards can be given to students who participate and provide relevant and useful knowledge to other students. This could enhance the knowledge sharing between students and encourage their cooperation. Students' knowledge of their effective participation which is also rewarded by their lecturers helps them to answer their peer questions.

A research conducted by Yong (25) shows that the awareness of the benefits of social media in academic field still moderate. This study shares the same opinion. Students and their families must be conscious of the use of social media. The university is recommended to hold a seminar or public lectures to increase public awareness. It could be increased also by cooperation with national television to produce materials that can lead to better understanding of the use of social media in the academic field. In this transition period, where the role of social media is still ambiguous, students can play a major role in enlightening their families with the role of social media.

Engagement of student in online peer learning leads to better academic achievement. The findings of this study support the belief by students that engaging with active and productive online learning will have a positive effect on their academic achievement. Albert Bandura (27) in the Social Cognitive Theory, pointed out that people can learn by observing and imitating each other and with positive reinforcement. In the context of this study, to produce such behaviour from students, they must be engaged in the learning using social media and online peer learning. The zone of proximal development in sociocultural theory, peer can collaborate to solve problems and teach each other. Vygotsky (26) pointed out that learning can take place between peers and their academic achievement can be influenced by the potential development as showed through problem solving under adult direction or in collaboration with more capable peers.

Collaboration between peer must be encouraged by rewards and by enforcing positive behaviour. The university and lecturers can play a vital role in this process. University can enlighten the students and encourage them to collaborate. Lecturers can assign groups to work together via social media. Developing this skill is important for students to shift from traditional 
or face-to-face collaboration to an online one. The benefits of online collaboration are the peers might be available at any time and can participate from anywhere. This flexibility could lead to better academic performance of the peer and better utilization and deployment of their time. The present study has found that collaboration between peer would result in higher academic achievement. This is in agreement with the conceptualization of Sociocultural Theory by Vygotsky (26). Vygotsky stated that learning developed as a direct consequence of social interaction. More in detail, Vygotsky confirmed that "knowledge is the first socially constructed and then internalized by individuals". Sociocultural theory can be realized in action in today's classroom through approaches of learning for instance collaborative learning. However, with the introduction of online peer learning, the collaboration can take place in an online environment and lead to similar results of peer teaching and collaborating with each other. As a result, this study confirms that collaboration between peer in online environment is valid and able to predict the academic achievement.

Similarly, the results of the present study are consistent with those of Wong (28) who studied the effects of collaborative learning on students' attitude and academic achievement in learning computer programming. The findings of that study revealed that students performed better on achievement and were more positive toward learning programming activities when they were working in collaborative groups than when they were working on the same activities individually. Elsewhere, Adekola (29) with the focus to collaborative learning method and its effect on students' academic achievement in reading comprehension found that male low achievers performed better than their female counterparts when exposed to collaborative learning in comprehension.

Government regulatory agencies which are accountable to supervise internet activities such as the MCMC in Malaysia and Ministry of Higher Education could also profit from these findings. This kind of study could be used as outline or improve any accessible guidelines on internet usage in general or predominantly focusing on online peer learning among the students. Implementation of social networking sites into education should be consider by the Ministry of Education, Malaysian Communication and Multimedia Commission, schools and other institution of higher learning since the students prefer to spend time on online peer learning. At this point, many changes are taking place in the education system of the country and certainly a new invention and introduction of learning through social media will bring benefits to the students. Thus the teachers need to be ready mentally and physically for the new changes to provide an excellent service and create good students who will be Malaysian future leaders.

\section{Conclusion}

Based on the findings of the study, there are positive significant low correlation between the variables measured. The highest correlation is between collaboration and academic achievement followed by the correlation between performance expectancy and academic achievement, engagement and academic achievement, social influence and academic achievement, peer feedback and academic achievement, and lastly, self-efficacy and academic achievement. Practical implications and recommendations were derived. As such, a few recommendations were 
given to enhance the engagement of students via online peer learning, for instance by given rewards for the active, productive and creative students by the lecturers. Mindful of the facts that students' online peer learning was an expected situation. Future studies could make comparison of the intensity, extent and nature of academic interaction of dependent use and independent use of online peer learning among the tertiary students. It is necessary to conduct further research by considering several factors. First, the online peer learning usages need to be compare by the differences in culture, social status and personality of the students. Second, future studies also need to consider on the differences in educational and grading systems among the states and the relationship with the usage of online peer learning. As such, studies which are related to online peer learning among tertiary students are few. It is recommended that future work expand the study and investigate the online peer learning from different perspectives with different unit of analysis. The future work is recommended to conduct a qualitative study where an interview with experts can be held to discover the dimensions and issues of online peer learning. This is because previous studies conducted quantitative studies and due to the fact that online peer learning is a new topic and still evolving. A qualitative approach could help in understanding the student usage of online peer learning via social media. Other methods could be to mediate a focus group where experts in peer learning can be asked to discuss the issue of tertiary students' online peer learning usage and its effect on academic achievement. From the findings, it can be reasoned out that it is possible when students would be given opportunities to collaborate, they can develop the sense of social presence through online peer learning in line with the social media tools they are using at the given time.

\section{Corresponding Author}

Norlizah Che Hassan (PhD) is a senior lecturer at Faculty of Educational Studies, University Putra Malaysia, 43450, Serdang, Malaysia. Email: norlizah@upm.edu.my

\section{Acknowledgement}

We are very grateful to all the participants for their contribution to this research, and to all who had contributed to this study.

\section{References}

Kushin, M. J., \& Yamamoto, M. (2010). Did Social Media Really Matter? College Students' Use Of Online Media and Political Decision Making in the 2008 Election. Mass Communication and Society, 13(5), 608-630.

Majid, S., \& Yuan, T. J. (2006). Information and Knowledge Sharing By Undergraduate Students In Singapore. Emerging Trends and Challenges in Information Technology Management, 1(2), 1057-1060.

Hashim, N. A., Abdullah, N. L., Isa, R. M., \& Janor, H. (2015). WhatsApp Messenger Application among Business Students in Malaysia- An Exploration. Jurnal Personalia Pelajar, 130-141.

Vézina, A. (2014). The role of social media in education: How Twitter Can Be Used in The Intermediate Classroom as a Tool for Collaborative Learning. A Research Paper Submitted in Conformity with The Requirements for the Degree of Master of Teaching Department of Curriculum, Teaching and Learning. Ontario Institute for Studies in Education of the 
Vol. 8, No. 4, 2019, E-ISSN: 2226-6348 @ 2019 HRMARS

University of Toronto.

Kiss, J. (2010). Facebook reaches 500 million users.

//www.theguardian.com/technology/2010/jul/21/facebook-500-million-users.

Keppell, M., Au, E., Ma, A., \& Chan, C. (2006). Peer Learning and Learning-Oriented Assessment in Technology-Enhanced Environments. Assessment \& Evaluation in Higher Education, 31(4), 453-464.

Razak, R. A., \& See, Y. C. (2010). Improving Academic Achievement and Motivation through Online Peer Learning. Procedia-Social and Behavioral Sciences, 9(0), 358-362.

Girasoli, A. J., \& Hannafin, R. D. (2008). Using Asynchronous AV Communication Tools to Increase Academic Self-Efficacy. Computers \& Education, 51(4), 1676-1682.

Kincheloe, J. L. (2008). Critical Pedagogy Primer. Peter Lang.

Al-Rahmi, W. M., Othman, M. S., \& Yusuf, L. M. (2015). Social Media for Collaborative Learning and Engagement: Adoption Framework in Higher Education Institutions in Malaysia. Mediterranean Journal of Social Sciences, 6(3 S1), 246-252.

Cochran, W. G. (1977). Sampling Technique. New York: John Wiley and Son Inc.

Ainin, S., Naqshbandi, M. M., Moghavvemi, S., \& Jaafar, N. I. (2015). Facebook Usage, Socialization and Academic Performance. Computers \& Education, 83(6), 64-73.

Sedek, M. (2014). Factors Influencing Utilization of Ubiquitous Technology among Undergraduates in Malaysian Technical Universities. (Doctoral Dissertation, UPM).

Sullivan, P., \& McDonough, A. (2007). Eliciting positive student motivation for learning mathematics. Paper presented at the Mathematics: Essential Research, Essential Practice: 30th Annual Conference of the Mathematics Education Research Group of Australasia, Hobart, Tasmania.

Wang, H. Y., \& Wang, S. H. (2010). User acceptance of mobile internet based on the Unified Theory of Acceptance and Use of Technology: Investigating the determinants and gender differences. Social Behavior and Personality: an international journal, 38(3), 415-426.

Cho, V., Cheng, T. C., \& Lai, W. M. (2009). The Role of Perceived User-Interface Design in Continued Usage Intention of Self-Paced E-Learning Tools. Computers \& Education, 53(2), 216-227.

Yeung, P., \& Jordan, E. (2006). Understanding the Continued Usage of Business E-Learning Courses in HK Corporations. In Education for the 21st Century-Impact of ICT and Digital Resources, volume 210, 245-254.

Korir, D. K., \& Kipkemboi, F. (2014). The Impact of School Environment and Peer Influences on Students' Academic Performance in Vihiga County, Kenya. International Journal of Huanities and Social Science, 4 (5): 240, 251.

Eamon, M. K. (2005). Social-Demographic, School, Neighborhood, and Parenting Influences on the Academic Achievement of Latino Young Adolescents. Journal of Youth and Adolescence, 34(2), 163-174.

Qin, L., Kim, Y., Hsu, J., \& Tan, X. (2011). The Effects of Social Influence on User Acceptance of Online Social Networks. International Journal of Human-Computer Interaction, 27(9), 885-899.

Ganotice Jr, F. A., \& King, R. B. (2014). Social Influences on Students' Academic Engagement and Science Achievement. Psychological Studies, 59(1), 30-35. 
INTERNATIONAL JOURNAL OF ACADEMIC RESEARCH IN PROGRESSIVE EDUCATION AND DEVELOPMENT

Vol. 8, No. 4, 2019, E-ISSN: 2226-6348 @ 2019 HRMARS

Ahmad, I., Saeed, M., \& Salam, M. (2013). Effects of Corrective Feedback on Academic Achievement of Students: Case of Government Secondary Schools in Pakistan. International Journal of Science and Research, 2(1), 36-40.

Hattie, J., \& Timperley, H. (2007). The power of feedback. Review of educational research, 77(1), 81-112.

O'Connell, B. (2010). "Enhancing Assessment Feedback. Practices in Accounting EducationIssues, Obstacles, and Reforms." Sydney: Australian Learning and Teaching Council, pp.178.

Yong, L. S., (2011). Awareness of Invasion of Privacy on Social Networking Site among Youth $n$ Malaysia: A Case Study of Facebook (Doctoral Dissertation, UTAR).

Vygotsky, L. S. (1986). Thought and Language. Cambridge. MA: MIT Press.

Bandura, A. (1986). Social Foundations of Thought and Action: A social cognitive theory. PrenticeHall, Inc.

Wong, K.-T, Teo, T., \& Goh, P.-S.-C. (2014). Development of the Interactive Whiteboard Acceptance Scale (IWBAS): An Initial Study. Educational Technology \& Society, 17(4), 268277.

Adekola, B. O. (2014). Collaborative Learning Method and Its effect on Students' Academic Achievement in Reading Comprehension. European Journal of Humanities and Social Sciences, 32(1), 1768-1775.

Infographic, (2014). (Cited on15/May/2016). Retrieved from:

http://socialmarketingwriting.com/tipssharing-infographic-facebook-twitterpinterestlinkedin/. 